NSL 09199

\title{
Region specific expression of furin mRNA in the rat brain
}

\author{
Robert Day ${ }^{\mathrm{a}}$, Martin K.-H. Schafer ${ }^{\mathrm{c}}$, William E. Cullinan ${ }^{\mathrm{d}}$, Stanley J. Watson ${ }^{\mathrm{d}}$, Michel Chrétien ${ }^{\mathrm{b}}$ and \\ Nabil G. Seidah ${ }^{\mathrm{a}}$
}

J.A DeSève Laboratories of 'Biochemical and ${ }^{b}$ Molecular Neuroendocrinology, Clinical Research Institute of Montreal, Montreal, Que. (Canada), 'Anatomisches Institut, Johannes Gutenberg-Universitat, Mainz (FRG) and dMental Health Research Institute, University of Michigan, Ann Arbor, MI 48109 (USA)

(Received 24 August 1992; Revised version received 2 October 1992; Accepted 2 October 1992)

Key words: Ventricle; Choroid plexus; Ependyma; Pineal; Olfactory bulb; Islands of Calleja; Convertase; Constitutive; In situ hybridization

\begin{abstract}
The distribution of furin mRNA was examined in the rat central nervous system. Northern blot analysis reveals the presence of a $4.4 \mathrm{~kb}$ band in all brain tissues examined. In situ hybridization analysis of frozen rat brain sections using a radioactively labeled antisense cRNA probe to rat furin demonstrated moderate to low levels of expression in both neuronal and non-neuronal tissue in all areas examined. Interestingly, higher levels of furin were expressed in selective regions which include the ventricles (the choroid plexus and ependymal cells), the islands of Calleja, the hippocampus and the pineal gland. The ubiquitous localization of furin in the brain is consistent with its postulated role as a vital convertase important in the processing of proproteins negotiating the constitutive pathway of secretion. However, the higher expression of furin mRNA in distinct brain areas suggests a more active role in the processing of proproteins synthesized in these tissues.
\end{abstract}

Substantial evidence has been documented classifying a family of subtilisin/Kexin-like proteinases as the convertases responsible for the activation of proproteins and prohormones at pairs of basic amino acids such as LysArg [14]. These include PC1, PC2 and furin [9, 12, 13, 15]. In mammals, furin was the first convertase to be identified due to its sequence homology with Kexin [2]. Furin was first suspected to be a receptor protein produced by the fur gene, so named because of its proximity to the $f e s / f p s$ oncogene $[9,15]$. The specificity of furin for cleavage at pairs of basic amino acids was demonstrated by its efficient cleavage of the pro-von Willebrand factor $[15,18]$, pro- $\beta$-nerve growth factor [2], proalbumin, and complement pro-C3 [8]. Furin mRNA has been demonstrated in all tissues tested and in many cells lines such as BSC40, COS, HepG2, Rinm5, GH3, and AtT-20, suggesting its ubiquitous expression $[9,11,15]$. The CNS distribution of furin has not been examined. The present study examines the expression of furin mRNA in the rat CNS by in situ hybridization histochemistry to better

Correspondence: R. Day, J.A. DeSève Laboratory of Biochemical Neuroendocrinology, Clinical Research Institute of Montreal, 110 Pine Avenue West, Montreal, Que. H2W 1R7, Canada. Fax: (1) (514) $987-$ 5542 . understand its potential role in the processing of proproteins in the brain.

Male Sprague-Dawley rats weighing 250-300 g were used. Rat brains were dissected, extracted for total RNA and Northern blot analysis or frozen by immersion in isopentane, sectioned $(15 \mu \mathrm{m})$ on a cryostat and treated for in situ hybridization histochemistry as previously described [4]. Mouse (m) PC1 and mPC2 cDNA clones [12, 13] were used to generate single-stranded antisense cRNA probes labeled with $\left[{ }^{32} \mathrm{P}\right] \mathrm{UTP}(800 \mathrm{Ci} / \mathrm{mmol})$ for the Northern blot analysis. The mPCl cRNA was 520 nts (specific activity of $1.05 \times 10^{5} \mathrm{Ci} / \mathrm{mmol}$ ) and the mPC2 cRNA was 342 nts (specific activity of $5.6 \times 10^{4}$ $\mathrm{Ci} / \mathrm{mmol}$ ). The furin $\mathrm{cRNA}$ probe was generated from a $1228 \mathrm{nts}$ cDNA clone obtained from a $\lambda \mathrm{gt} 11$ rat (r) liver library and subcloned into pSP72 (Promega). The clone corresponds to the previously described rfurin cDNA [7] from 1111 to $2338 \mathrm{bp}$. The rfurin cRNA was $320 \mathrm{nts}$ (spec. act. of $4.9 \times 10^{4} \mathrm{Ci} / \mathrm{mmol}$ using $\left[{ }^{32} \mathrm{P}\right] \mathrm{UTP}$ ). For in situ hybridization studies, a $1228 \mathrm{nts}$ rfurin cRNA was prepared using $\left[{ }^{35} \mathrm{~S}\right] \mathrm{UTP}$ (spec. act. of $3.0 \times 10^{5} \mathrm{Ci} / \mathrm{mmol}$ ) and partially hydrolyzed before use for in situ hybridization. Similarly a rPC1 cRNA (492 nts, spec. act. $2.5 \times 10^{5}$ $\mathrm{Ci} / \mathrm{mmol}$ ) and $\mathrm{rPC} 2 \mathrm{cRNAs}$ (450 nucleotides spec. act. of $2.4 \times 10^{5} \mathrm{Ci} / \mathrm{mmol}$ ) were prepared for the in situ hybridization studies [4]. Controls for in situ hybridization were pretreatment with RNase A prior to hybridization 


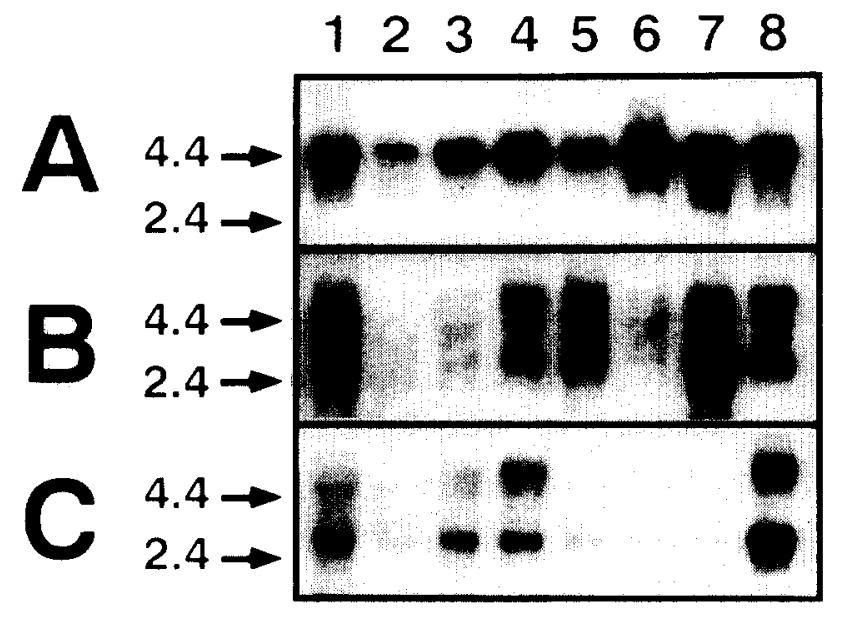

Fig. 1. Northern blot analysis of total RNA extracted from various rat brain regions and pituitary. A: furin; $\mathrm{B}: \mathrm{PC} 1$; $\mathrm{C}$ : PC2. Lane 1, cortex; lane 2, hippocampus; lane 3, striatum; lane 4, thalamus; lane 5 , hypothalamus; lane 6, cerebellum; lane 7, anterior pituitary; lane 8, neurointermediate lobe. In each lane was loaded $5 \mu \mathrm{g}$ of total RNA (except for lane $8,2 \mu \mathrm{g}$ of total RNA). X-ray exposure times were 48,8 and $2 \mathrm{~h}$ for (A) furin, (B) PC1 and (C) PC2, respectively. Size markers are in kb.

or probing adjacent sections with the sense strand probes of the same size and specific activity. Specific labeling was never encountered in these experiments.

The Northern gel analysis of various rat brain regions is shown in Fig. 1. A band migrating at $4.4 \mathrm{~kb}$ is detected after blot hybridization with the rfurin cRNA probe in each of the brain regions examined (Fig. 1A), consistent with the size reported in peripheral tissues and cell lines [9]. A comparison is shown with $\mathrm{PCl}$ and $\mathrm{PC} 2 \mathrm{mRNA}$ expression in these same brain regions (Fig. 1B,C). As previously described $[4,12,13]$, both $\mathrm{PC} 1$ and $\mathrm{PC} 2$ mRNAs appear as two bands each, migrating mainly at $2.8-3.0 \mathrm{~kb}$ and to a lesser extent at $5.0 \mathrm{~kb}$. The expression of furin mRNA appears to be relatively even in each of the tissues shown as compared to $\mathrm{PC1}$ and $\mathrm{PC} 2 \mathrm{mRNA}$ levels. Thus, while PC1 and PC2 exhibit variable levels of expression, furin mRNA is detected in every region examined. This expression pattern is consistent with the reported ubiquitous nature of furin in the periphery and cell lines examined. Based on the specific activities of each probe used and exposure times required, we estimate the abundance of the convertases as follows: $\mathrm{PC} 2>\mathrm{PC} 1>>$ furin. We further investigated the precise brain localization of furin mRNA in the brain using in situ hybridization histochemistry.

The distribution of furin mRNA is shown in Fig. 2A in a representative sagital rat brain section. The comparison is made with $\mathrm{PC} 1$ (Fig. 2B) and $\mathrm{PC} 2$ (Fig. 2C) mRNA distribution. As previously described $\mathrm{PCl}$ and PC2 mRNAs have a widespread CNS distribution which is restricted to neuronal elements [3,10-13]. The highest

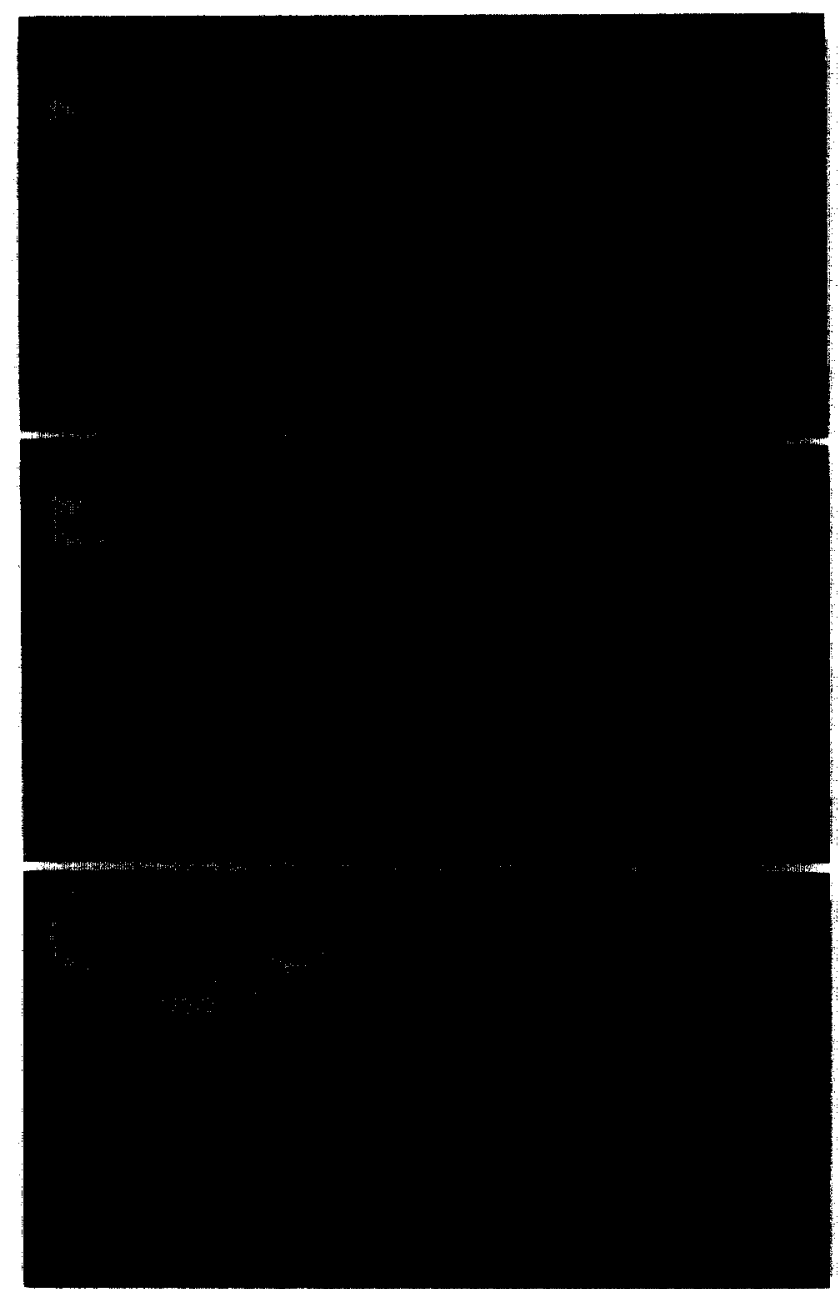

Fig. 2. Low power dark field photomicrograph of rat brain sagital sections treated for in situ hybridization histochemistry. A: furin; B: $\mathrm{PCl}$; C: PC2. CTX, cortex; CP, choroid plexus; EP, ventricular ependyma; HC, hippocampus; LH, lateral hypothalamus; SON, supraoptic nucleus; CBL, cerebellum, ST, striatum; LS, lateral septum; $\mathrm{SC}$, superior colliculus; IC, inferior colliculus; TH, thalamus. Note the higher levels of expression of furin mRNA in the ependyma and choroid plexus, however no expression of either $\mathrm{PC} 1$ or $\mathrm{PC} 2$ is detected in these areas. The autoradiography exposure time for each sagital section was 30 days.

levels of PC1 appear in the hypothalamic (supraoptic nucleus and lateral hypothalamus) and cortical areas, while PC2 expression is highest in the thalamus and cortex, consistent with the Northern gel analysis (compare with Fig. 1). However, furin mRNA is clearly widespread, at relatively lower levels, but some select brain regions, which include both neuronal and non-neuronal cells, express much higher levels of furin. In Fig. 2A, note the higher ventricular expression of furin (ependyma and choroid plexus), while $\mathrm{PC} 1$ and $\mathrm{PC} 2$ are undetectable in this same area (Fig. 2B,C). The distribution of furin mRNA in this ventricular region is shown in a coronal section (Fig. 3A). The choroid plexus expresses very high levels of furin mRNA (Fig. 3A,D). In Fig. 3A we note the 


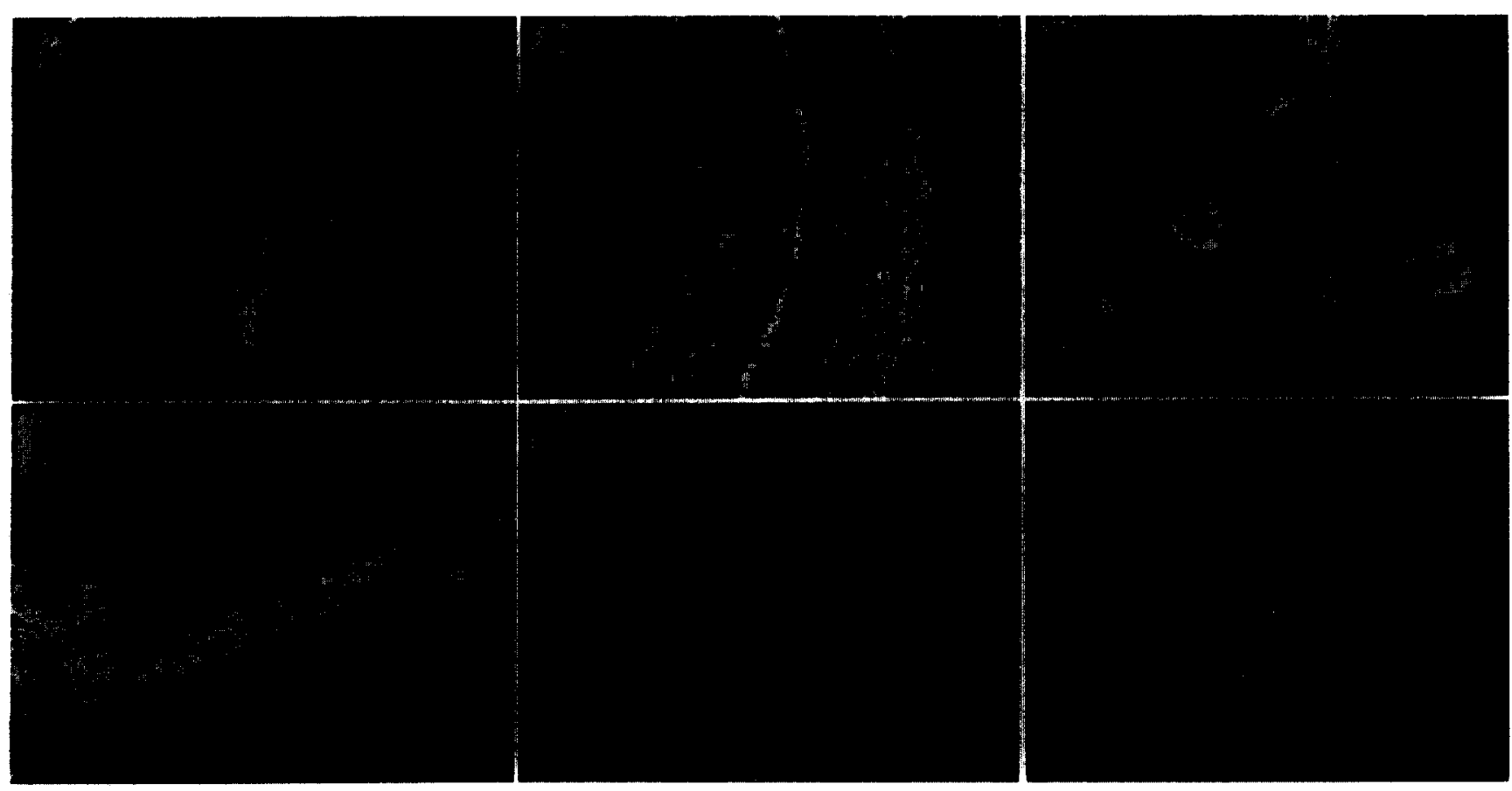

Fig. 3. In situ hybridization dark field photomicrographs of rat brain areas expressing highest levels of furin mRNA. A: coronal section showing ubiquitous (yet not homogeneous) furin mRNA distribution in the cortex (CTX), the lateral ventricle (LV) and the hippocampus (HC). B: horizontal section demonstrating high expression levels of furin in the olfactory bulb. Gl, glomerular layer; EPI, external plexiform layer; $\mathbf{M}$, mitral cell layer; T, tufted cells; IGl, internal granule layer. C: furin mRNA distribution in the Islands of Calleja (ICj). Higher levels are observed in the ICj as compared to surrounding brain areas which are also specifically labelled. D: horizontal rat brain section showing the detailed localization of furin mRNA in the lateral ventricle. Note the high expression levels in the ventricular ependyma (EP) and the choroid plexus (CP). E: example of a control section treated with a sense strand furin probe of equal length and specific activity to that shown in (D). No specific grains were observed in the ventricular or surrounding brain areas. $\mathrm{F}$ : high expression levels of furin mRNA in the pineal gland ( $\mathrm{Pi}$ ). The autoradiography exposure time was 30 days.

widespread distribution of furin mRNA in other regions such as the hippocampus and the cortex. Although the distribution of furin mRNA in cortical cells is ubiquitous, it is clearly not equal (Fig. 3A). Analysis of these cortical regions at high magnification reveals furin mRNA in both neurons and glial cells, with a higher expression in neurons (data not shown). Other brain regions showing heterogeneous furin expression are the olfactory bulbs (Fig. 3B), the pineal gland (Fig. 3F) and the islands of Calleja (Fig. 3C). Along with the ventricles, these regions express the highest levels of furin mRNA in the rat brain.

The overall pattern of furin mRNA expression indicates a vital role in general cellular function. Furin cleaves a variety of proproteins at pairs of basic residues, including pro-von Willebrand factor $[15,18]$, pro- $\beta$ NGF [2], pro-albumin, and complement pro-C3 [8]. The sequence Arg-X-Lys/Arg-Arg is an important motif as a signal for precusor cleavage by furin $[5,17]$. This motif is found is many proproteins which are secreted via the constitutive pathway of secretion $[1,6]$. Also, the structure of furin includes a transmembrane domain [16], indicating this enzyme may be membrane anchored along the pathway of secretion, most probably in the trans-
Golgi network. It was thus hypothesized that furin is a processing enzyme activating proproteins, negotiating the constitutive pathway of secretion. Our results support this notion, since the in situ hybridization analysis demonstrates furin expression in all areas, in both neurons and non-neuronal cells. However, it is important to note that the cellular distribution of furin mRNA levels is not homogeneous. The ventricular ependymal cells, the choroid plexus, olfactory bulb cells (tufted, mitral, granule), the pineal cells, and neurons of the Islands of Calleja are examples where furin mRNA is expressed at much higher levels than other cells. The function of furin is most likely the activation of distinct proproteins via cleavage at pairs of basic residues, and the higher levels of furin expression may indicate that in these cells furin has a higher rate of posttranslational activity and hence of proprotein processing. The importance of furin in these specific cells requires the knowledge of the nature of the substrates which are cleaved by this convertase. The correlation of furin mRNA levels and that of potential substrates might be a step in that direction.

We thank Christian Charbonneau for his invaluable contribution in preparing the figures and Ms. Sylvie 
Emond for secretarial help. This work was supported by the Medical Research Council of Canada; MT-11268 to R.D.; PG2 to N.G.S. and M.C., the J.A. DeSève Succession to M.C. and NIDA (RO1 DA00265-12): and NIMH (MH42251-06) to S.J.W. R.D. is a scholar of the Fonds de la Recherche en Santé du Québec.

1 Barr, P.J., Mammalian subtilisins: the long-sought dibasic processing endoproteases, Cell, 66 (1991) 1-3.

2 Bresnahan, P.A., Leduc, R., Thomas, L., Thorner, J., Gibson, H.L., Brake, A.J., Barr, P.J. and Thomas, G., Human fur gene encodes a yeast KEX2-like endoprotease that cleaves pro- $\beta$-NGF in vivo, $J$. Cell Biol., 111 (1990) 2851-2859.

3 Cullinan, W.E., Day, N.C., Schafer, M.K.-H., Day, R., Seidah, N.G., Chrétien, M., Akil, H. and Watson, S.J., Neuroanatomical and functional studies of peptide precursor processing enzymes, Enzyme, 45 (1991) 285-300.

4 Day, R., Schafer, M.K.-H., Watson, S.J., Chrétien, M. and Seidah, N.G., Distribution and regulation of the prohormone convertases PC1 and PC2 in the rat pituitary, Mol. Endocrinol., 6 (1992) 485497.

5 Hosaka, M., Nagahama, M., Kim, W.S., Watanabe, T., Hatsuzawa, K., Ikemizu, J., Murakami, K. and Nakayama, K., Arg-XLys/Arg-Arg motif as a signal for precursor cleavage catalyzed by furin within the constitutive secretory pathway, J. Biol. Chem., 266 (1991) 12127-12130.

6 Hutton, J.C., Subtilisin-like proteinases involved in the activation of proproteins of the eukaryotic secretory pathway, Curr. Opin. Biol., 2 (1990) 1131-1142.

7 Misumi, Y., Sohda, Y. and Ihehara, Y., Sequence of the cDNA encoding rat furin a possible propeptide processing endoprotease, Nucleic Acids Res., 18 (1990) 22.

8 Misumi, Y., Oda, K., Fujiwara, T., Takami, N., Tashiro, K. and Ikehara, Y., Functional expression of furin demonstrating its intracellular localization and endoprotease activity for processing proalbumin and complement pro-C3, J. Biol. Chem., 266 (1991) 16954 16959.

9 Roebroek, A.J.M., Schalken, J.A., Leunissen, J.A.M., Onnekink, C., Gloemers, H.P.J. and Van de Ven, W.J.M., Evolutionary conserved close linkage of the $c$-feslfps proto-oncogene and genetic sequences encoding a receptor-like protein, EMBO J., 5 (1986) 21972202.
10 Schafer, M.K.H., Day, R., Cullinan, W.E., Chrétien, M.C., Seidah, N.G. and Watson, S.J., Gene expression of prohormone and proprotein convertases in the rat CNS: a comparative in situ hybridization analysis, $J$. Neurosci., in press.

11 Schalken, J.A., Roebroek, A.J.M., Oomen, P.P.C.A., Wagenaar, S.S.C., Debruyne, F.M.J. and Van de Ven, W.J.M, Fur gene expression as a discriminating marker for small cell and non-small cell lung carcinomas, J. Clin. Invest., 80 (1987) 1545-1550.

12 Seidah, N.G., Gaspar, L., Mion, P., Marcinkiewicz, M., Mbikay, M. and Chrétien, M., cDNA sequence of two distinct pituitary proteins homologous to Kex2 and Furin gene products: tissue-specific mRNAs encoding candidates for pro-hormone processing proteinases, DNA, 9 (1990) 415-424.

13 Seidah, N.G., Marcinkiewicz, M., Benjannet, S., Gaspar, L., Beaubien, G., Mattei, M.G., Lazure, C., Mbikay, M. and Chrétien, M., Cloning and primary sequence of a mouse candidate prohormone convertase $\mathrm{PCl}$ homologous to $\mathrm{PC} 2$, Furin and Kex2: distinct chromosomal localization and messenger RNA distribution in brain and pituitary compared to PC2, Mol. Endocrinol., 5 (1991) 111-122.

14 Seidah, N.G. and Chrétien, M., Proprotein and prohormone convertases of the subtilisin family: recent developments and future perspectives, Trends Endocrinol. Metab., 3 (1992) 133-140.

15 Van de Ven, W.J.M., Voorberg, J., Fontijn, R., Pannekoek, H., Van den Ouweland, A.M.W., Van Duijnhoven, H.L.P., Roebroek, A.J.M. and Siezen R.J., Furin is a subtilisin-like proprotein processing enzyme in higher eukaryotes, Mol. Biol. Rep., 14 (1990) 265275.

16 Van Den Ouweland, A.M.W., Van Duijnhoven, H.L.P., Keizer, G.D., Dorssers, L.C.J. and Van De Ven, W.J.M., Structural homology between the human fur gene product and the subtilisin-like protease encoded by yeast KEX2, Nucleic Acids Res., 18 (1990) 664.

17 Watanabe, T., Nakagawa, T., Ikemizu, J., Nagahama, M., Murakami, K. and Nakayama, K., Sequence requirements for precursor cleavage within the constitutive secretory pathway, J. Biol. Chem., 267 (1992) 8270-8274.

18 Wise, R.J., Barr, P.J., Wong, P.A., Kiefer, M.C., Brake, A.J. and Kaufman, R.J., Expression of a human proprotein processing enzyme: correct cleavage of the von Willebrand factor precursor at a paired basic amino acid site, Proc. Natl. Acad. Sci. USA, 87 (1990) 9378-9382. 